\title{
Heat Resistivity of Stainless Steel Fiber Produced by Coiled Sheet Shaving
}

\author{
KANEKO Masao ${ }^{*}$, LEE Junjae, IMAMURA Masato, and \\ YANAGISAWA Akira
}

\author{
Faculty of Engineering, Nippon Institute of Technology, \\ 4-1 Gakuendai, Miyashiro-machi, \\ Minami Saitama-gun, Saitama 345-8501, Japan
}

Based on Journal of the Textile Machinery Society of Japan, Vol.53, No.6, T147-T153(2000-6)

\begin{abstract}
In order to improve the efficiency of automobiles, energy equipment, and various combustion equipment, it is necessary to raise their operating temperatures. Heat resistance to high temperature is thus strongly required in the filters that are used for these machines. In answer to such demands, the $20 \mathrm{Cr}-5 \mathrm{Al}$ stainless steel was developed for the metal honeycomb of automobiles. Use of fibers produced from $20 \mathrm{Cr}-5 \mathrm{Al}$ stainless steel at low costs by coiled sheet shaving methods for high temperature filters is expected. In this study, the heat resistance of the $20 \mathrm{Cr}-5 \mathrm{Al}$ stainless steel fiber was compared with that of normal stainless steel fibers. The results show that while normal stainless steel fiber becomes powdery when maintained at $1173 \mathrm{~K}, 21.6 \mathrm{ks}$, the $20 \mathrm{Cr}-5 \mathrm{Al}$ stainless steel fiber retains flexible features even at $1373 \mathrm{~K}, 360 \mathrm{ks}$.
\end{abstract}

Keywords: Metal fiber, Shaved fibers, Stainless steel, Heat resistivity, Filter

\section{Introduction}

In the recent years, the operating temperatures of automobiles, energy equipment, and various combustion equipment are being raised to improve their efficiency, resulting in growing demands for heat resistance to high temperature of the filters used for automobiles and equipments. Fiber materials are mainly used in the manufacture of filters, and consequently demands for heat resistance to high temperature are growing for these fiber materials. One typical example of fibers with heat resistance to high temperature is the ceramics fiber. Many problems are however encountered in the use of ceramic fiber because it is brittle and hard-to-machine. Compared to ceramic fibers, metal fibers offer many advantages such as good bending, sintering, and welding properties, but one of its drawbacks is poor heat resistance to high temperature.

Recently, 20Cr-5Al stainless steel was developed as a metal material with excellent heat resistance to high temperature. Currently, there are two general ways of producing fibers from metal; one is the bundle-drawing method ${ }^{[1]}$ and the other is the wire cut method ${ }^{[2]}$. When fibers are obtained from this material using the former method, the material yield in post-processes is poor owing to the low chemical resistance of the material. This results in high costs of the metal fiber, and consequently the purpose of use the material is restricted. In the case of the wire cut method, high quality fibers which are suitable for the above mentioned applications are difficult to manufacture. However with the hot water soluble resin coated coil shaving method ${ }^{[3,4]}$, fibers can be produced at low costs from thin sheets about $50 \mu \mathrm{m}$ thick massproduced for metal honeycomb. Though heat resistance for a sheet of $20 \mathrm{Cr}-5 \mathrm{Al}$ stainless steel sheet has been investigated in several studies ${ }^{[5,6,7]}$, heat resistance has not been confirmed for $20 \mathrm{Cr}-5 \mathrm{Al}$ stainless steel fibers with considerably different specific surface areas. In this study, we obtained fibers from six types of stainless steel: normal SUS304, SUS316L, and SUS430, and three types of $20 \mathrm{Cr}-5 \mathrm{Al}$ stainless steel containing different types of rare earth elements, and investigated the tensile strength of the fibers after heat resistance tests to compare their heat resistances.

\section{Experimental Conditions}

Figure 1 shows how the metal fiber is produced by the coiled sheet shaving method. With this method, thin metal of about $0.01 \mathrm{~mm}$ to $0.15 \mathrm{~mm}$ thick is coiled around the spindle of a shaving machine. As the sample material, we used three types of $20 \mathrm{Cr}-5 \mathrm{Al}$ stainless steel materials containing different types of rare earth elements in small amounts. The three types were type A containing La $(0.08 \%)$, type B containing Y $(0.1 \%)$, and type C containing $\mathrm{Ce}(0.081 \%)$. For comparison purpose, we also used the normal stainless steel SUS304, SUS316L, and SUS430. The sheet thickness ( $t$ ) of A, B, and C was

* Corresponding author Fax:0480-33-7645,E-mail:mkaneko@nit.ac.jp 


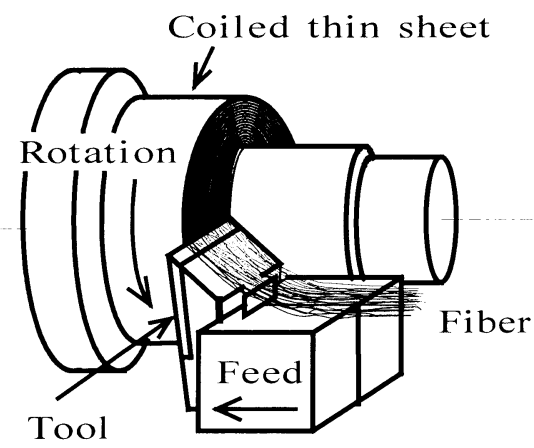

Fig.1 Schematic illustration of coiled sheet shaving method

Table 1 Experimental conditions

\begin{tabular}{|l|l|}
\hline Cutting tool & Sintered carbide tool (P20) \\
\hline $\begin{array}{l}\text { Cutting } \\
\text { conditions }\end{array}$ & $\begin{array}{l}\text { Rake angle } \gamma: 20 \sim 38^{\circ} \\
\text { Back clearance angle } \alpha: 10^{\circ} \\
\text { Approach angle } \phi: 2^{\circ}\end{array}$ \\
& $\begin{array}{l}\text { Cutting speed v:80m/min } \\
\text { Feed rate S:20 } \mu \mathrm{m} / \mathrm{rev} \\
\text { Width of cut W:20mm } \\
\text { Water soluble coolant } \\
\text { (Castrol SUPERDGE B7) }\end{array}$ \\
\hline Heat treatment & $\begin{array}{l}\text { Temperature Tt:298,473,673 } \\
873,1073,1173,1273,1373 \mathrm{~K}\end{array}$ \\
& $\begin{array}{l}\text { Holding time Ht:3.6,10.8, } \\
21.6,36,180,360 \mathrm{ks}\end{array}$ \\
\hline $\begin{array}{l}\text { Work material } \\
\text { (Stainless steel) }\end{array}$ & $\begin{array}{l}\text { SUS304,SUS316L,SUS430 } \\
\text { 20Cr-5Al A } \\
\text { A (La), B (Y), C (Ce) }\end{array}$ \\
\hline Sheet thickness & $\mathrm{t}=0.05,0.135,0.15 \mathrm{~mm}$ \\
\hline
\end{tabular}

set at $0.05 \mathrm{~mm}, 0.135 \mathrm{~mm}$, and $0.15 \mathrm{~mm}$, respectively. Fibers were produced from these samples under the conditions shown in Table 1.

Figure 2 shows the external view and cross section of fibers produced by cutting the edges of sheet metal using the coiled sheet shaving method. The length of the rectangular cross section is equivalent to the sheet thickness of the coil, while the width is equal to the thickness of the fiber, which depends on the feed rate of the tool. Both sides of this fiber cross section were rolled surfaces, where the lower surface is the cut surface and the upper surface is the freely generated surface during cutting. As metal fibers have non-circular cross section, the area of this rectangular cross section was normally converted to the cross section of a circle and the diameter of the circle was taken as the equivalent diameter of the fiber (d). When the feed rate of the tool was set at $20 \mu$ $\mathrm{m} / \mathrm{rev}$, the equivalent diameter of the fiber obtained from the respective sheet thickness was $d=35 \mu \mathrm{m}$ at a sheet thickness $\mathrm{t}$ of $0.05 \mathrm{~mm}, 85 \mu \mathrm{m}$ at a sheet thickness of $\mathrm{t}=0.135 \mathrm{~mm}$, and $90 \mu \mathrm{m}$ at a sheet thickness of $\mathrm{t}=0.15$ $\mathrm{mm}$. In the experiments, metal fibers of these equivalent diameters were used to evaluate the dependence of heat resistance on fiber diameter. The rake angle of the tool
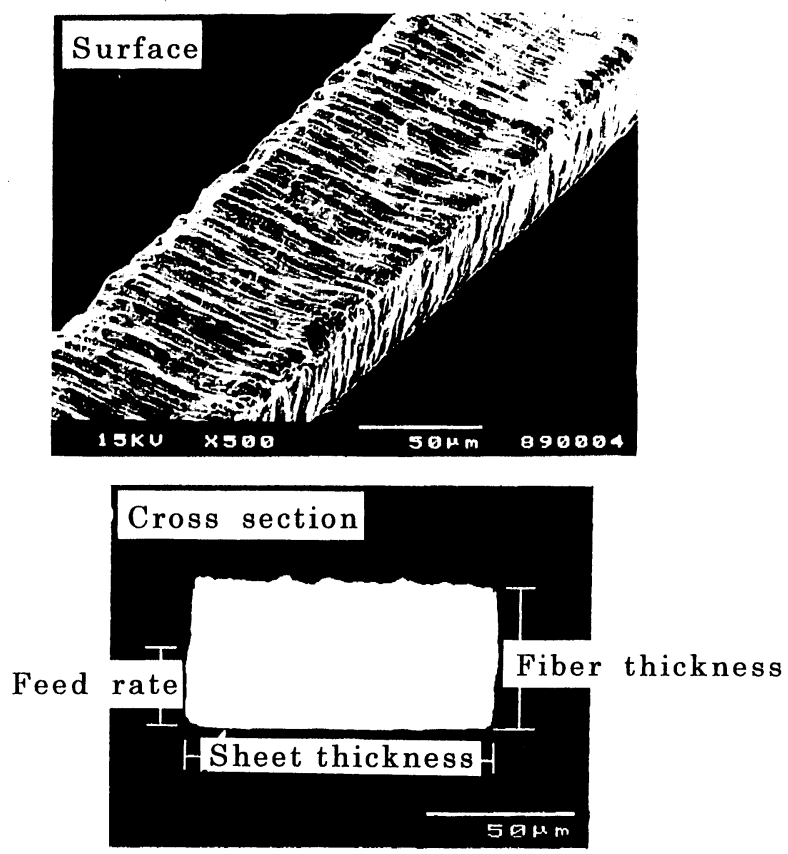

SUS304, $\mathrm{t}=0.1 \mathrm{~mm}, \mathrm{~V}=80 \mathrm{~m} / \mathrm{min}, \mathrm{S}=20 \mu \mathrm{m} / \mathrm{rev}, \quad \gamma=32^{\circ}$

Fig.2 Enlarged surface and cross section of fiber produced by coiled sheet shaving

was set at 32 degrees at a sheet thickness of $\mathrm{t}=0.05 \mathrm{~mm}$, and 30 degrees at sheet thicknesses $\mathrm{t}=0.135$ and $0.15 \mathrm{~mm}$. This is the rake angle at which fibers obtained were most round and had excellent and flexible properties at the tool feed rate of $20 \mu \mathrm{m} / \mathrm{rev}$.

The fibers obtained were processed using an electrical furnace in the atmospheric environment at the following temperatures; room temperature, $473 \mathrm{~K}, 673 \mathrm{~K}, 873 \mathrm{~K}$, $1073 \mathrm{~K}, 1173 \mathrm{~K}, 1273 \mathrm{~K}, 1373 \mathrm{~K}$, and the holding time was varied from $3.6 \mathrm{ks}, 10.8 \mathrm{ks}, 21.6 \mathrm{ks}, 36 \mathrm{ks}, 180 \mathrm{ks}$ to 360 ks. After cooling in the furnace, the tensile strength of the fibers were measured using the TCM-200 tension tester of Shinko Tsushin at the tensile speed of $5 \mathrm{~mm} / \mathrm{min}$. To investigate the breaking strength when used in high temperature environment, the heat resistance of the fibers was evaluated by a tensile test. Furthermore, after the heat resistance test, the fiber surface was observed by SEM, and the oxidized state of the fiber surface was checked by X-ray diffractmeter.

\section{Experimental Results and Discussion}

\subsection{Heat Resistance of Normal Stainless Steel Fibers}

First, experiments were carried out on the heat resistance of normal stainless steel fibers obtained using the coiled sheet shaving method. The experiments were carried out at the above processing temperatures and held for $3.6 \mathrm{ks}, 10.8 \mathrm{ks}$, and $21.6 \mathrm{ks}$. The fibers were then cooled in the furnace to the atmospheric temperature, and measured the fiber tensile strength. Figures 3, 4, and 5 


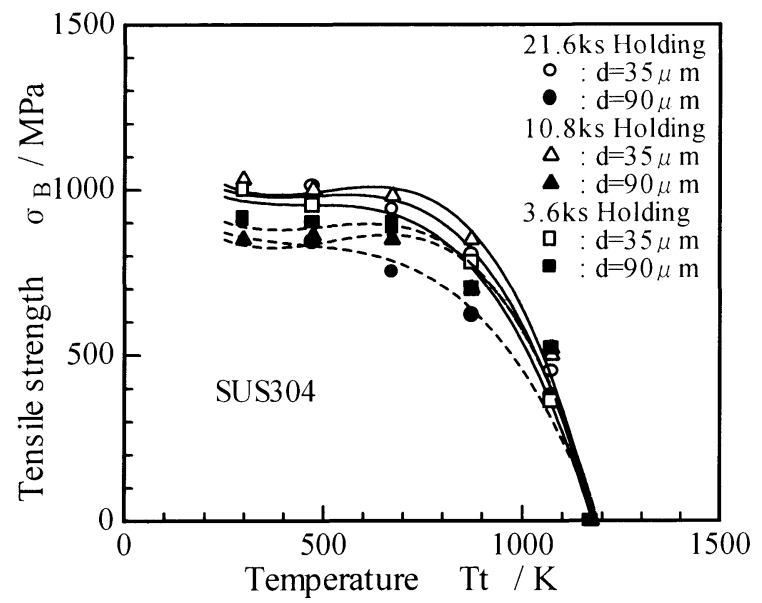

Fig.3 Relation between tensile strength and temperature at different equivalent diameters and holding times (SUS304)

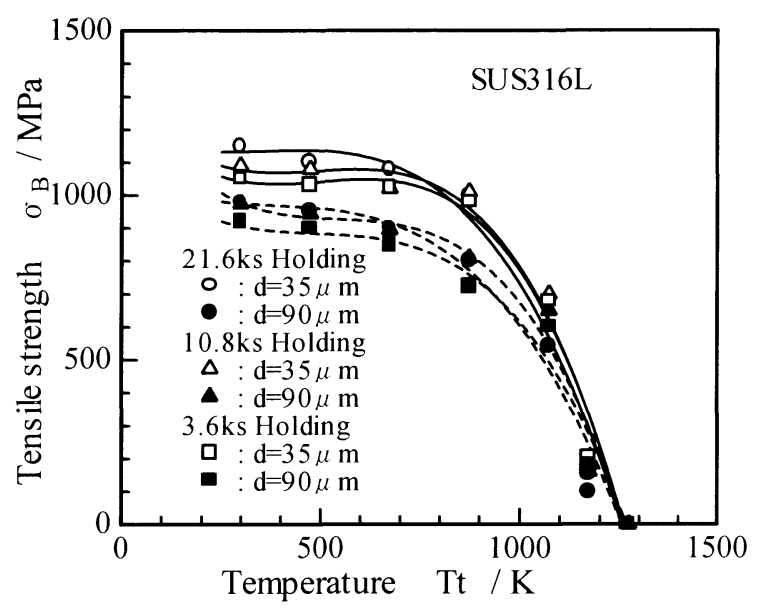

Fig.4 Relation between tensile strength and temperature at different equivalent diameters and holding times (SUS316L)

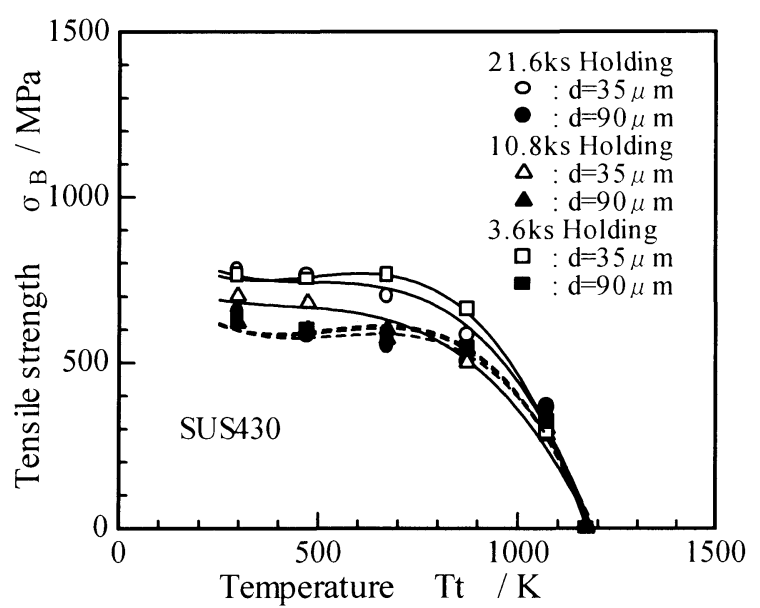

Fig.5 Relation between tensile strength and temperature at different equivalent diameters and holding times (SUS430) show the measurement results of processing temperature vs. tensile strength. The tensile strength was found to decrease suddenly at processing temperatures higher than $873 \mathrm{~K}$ for the SUS304, SUS316L, and SUS430 stainless steels, and SUS304 and SUS430 became completely powdery at $1173 \mathrm{~K}$, and SUS316L at $1273 \mathrm{~K}$. For these normal stainless steel fibers, tensile strength was found to decrease because they become brittle at high temperature, owing to the formation of large crystal particles, oxidization of the external layer, or peeling off of the oxidized film ${ }^{[8]}$. Furthermore, oxidization was found to spread to the center of the fiber, and result in the powdery state shown in Figs. 6(a) and (b). No significant difference was seen in the relation between tensile strength and temperature between the three stainless steels at different holding times. At holding times above $3.6 \mathrm{ks}$ in this experiment, the same drop in tensile strength was seen at each processing temperature. Furthermore, in low temperature ranges below $873 \mathrm{~K}$, the smaller the equivalent diameter, in other words, the smaller the sheet thickness, the greater the tensile strength. In areas with little effect of the oxidization, a small sheet thickness caused a large draft in the rolling process during the manufacture of sheet metal. The difference in the work hardening of the material itself was believed to manifest as the difference in fiber strength.

\subsection{Heat Resistance of 20Cr-5Al Stainless Steel Fiber}

Next, an experiment was carried out on the heat resistance of the type A $20 \mathrm{Cr}-5 \mathrm{Al}$ stainless steel sample containing the La under the same conditions as the normal stainless steels. Figure 7 shows the experiment results. Like the normal stainless steels, the fiber strength was found to decrease with a rise in the processing temperature. At $1373 \mathrm{~K}$ and a holding time of $21.6 \mathrm{ks}$, the fiber strength was about $350 \mathrm{MPa}$, and no breakage of the fiber was seen as shown in Fig. 6 (c). The tensile strength
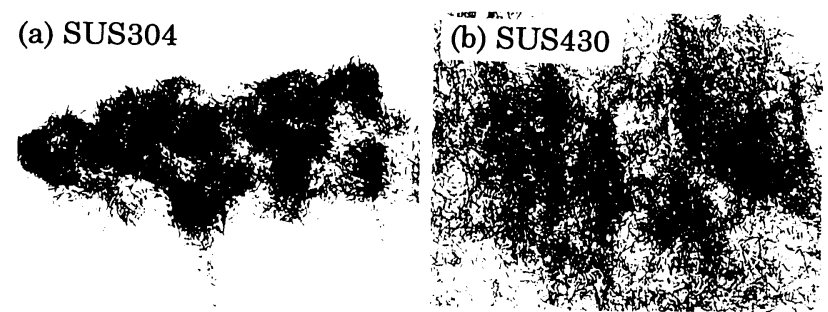

(c) $20 \mathrm{Cr}-5 \mathrm{Al}$

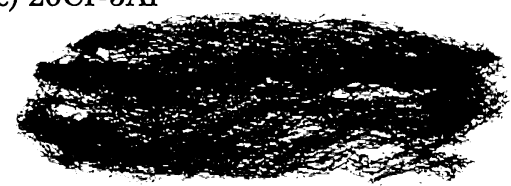

(a),(b): Temperature $1173 \mathrm{~K}$, Holding time $3.6 \mathrm{ks}$

(c): Temperature $1373 \mathrm{~K}$, Holding time $21.6 \mathrm{ks}$

Fig.6 Appearance of fiber after heat durability test 


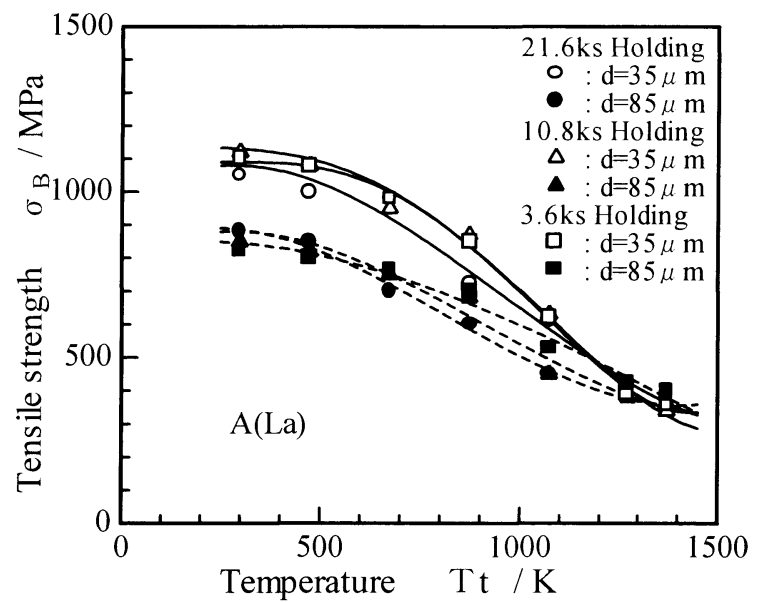

Fig.7 Relation between tensile strength and temperature

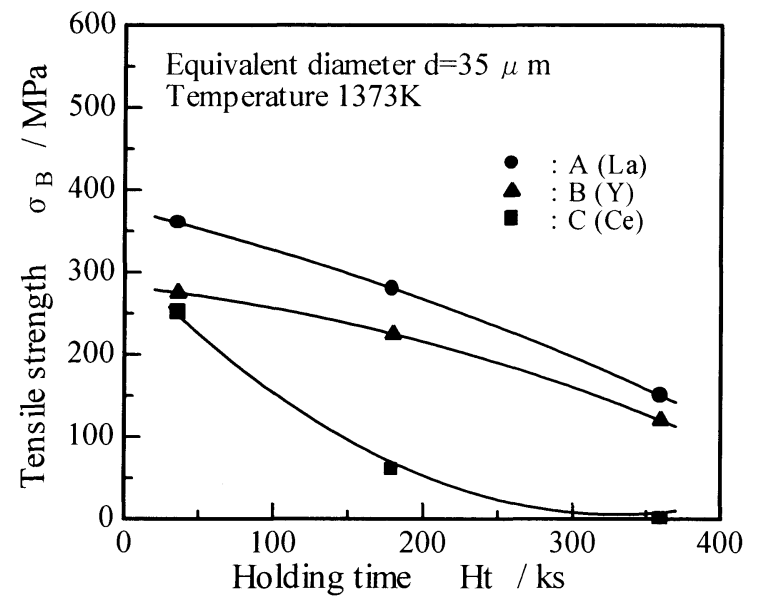

Fig.8 Relation between tensile strength and holding time for different rare earth elements

test showed a 5 to $10 \%$ elongation and confirmed that the type A stainless steel can be stretched and repeatedly bent by about several times. At the temperatures below $1173 \mathrm{~K}$, when the equivalent diameter is small, the fiber strength is large and depends on the machining hardness obtained by rolling. However when the temperature was above $1173 \mathrm{~K}$, no difference due to the equivalent diameter was found.

Next, the heat resistances of the type A (La), type B (Y), and type $\mathrm{C}(\mathrm{Ce})$ stainless steels were compared. Figures 8 and 9 show the changes in the tensile strength when the holding time was varied up to $360 \mathrm{ks}$ at a fixed processing temperature of $1373 \mathrm{~K}$. When the equivalent diameter was small $(35 \mu \mathrm{m})$, the type A stainless steel containing La showed the greatest heat resistance. At the holding time of $360 \mathrm{ks}$, the tensile strength was $150 \mathrm{MPa}$. The type $\mathrm{B}$ stainless steel containing $\mathrm{Y}$ showed a tensile strength of $120 \mathrm{MPa}$, but the type $\mathrm{C}$ stainless steel containing $\mathrm{Ce}$ showed a sudden decrease in the fiber tensile strength at the holding time of $180 \mathrm{ks}$ to $50 \mathrm{MPa}$. It was very brittle at the holding time of $360 \mathrm{ks}$, confirming that the fiber strength and shape required

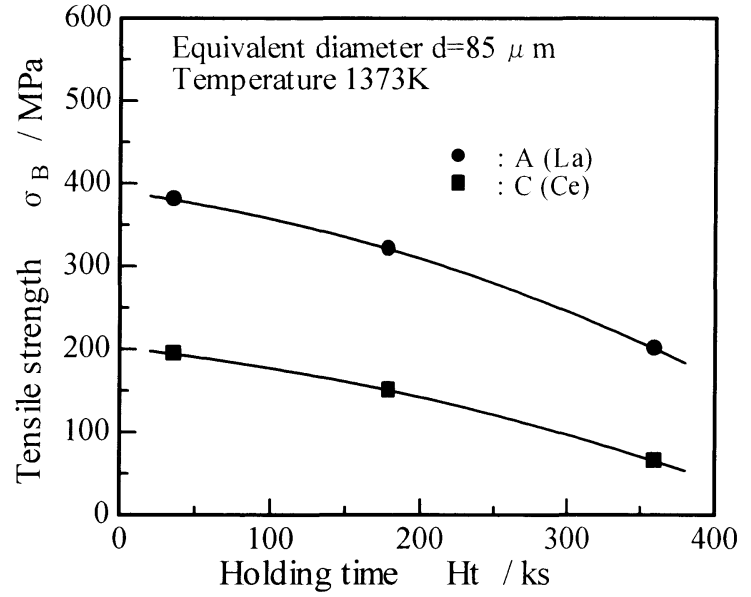

Fig.9 Relation between tensile strength and holding time for different rare earth elements
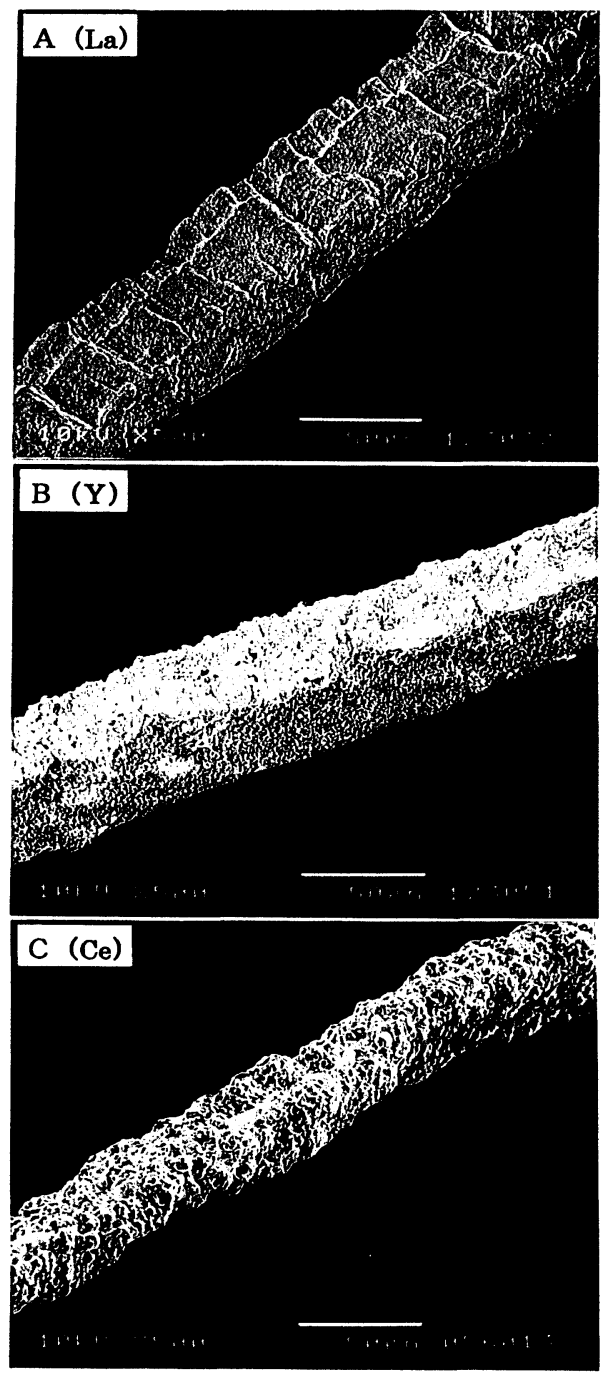

Temperature $1373 \mathrm{~K}$, Holding time $360 \mathrm{ks}, \mathrm{d}=35 \mathrm{um}$

Fig.10 Appearance of fiber after heat durability test 


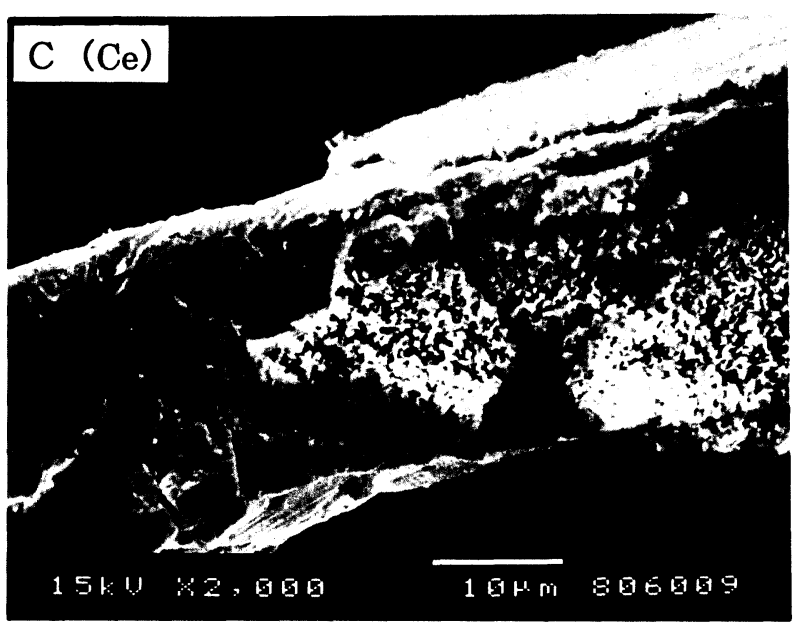

Temperature $1373 \mathrm{~K}$, Holding time $360 \mathrm{ks}, \mathrm{d}=35 \mathrm{um}$

Fig. 11 Morphology of $\mathrm{Al}_{2} \mathrm{O}_{3}$ layer film, and fibers containing La were especially found to have good film adhesion. However, fibers containing $\mathrm{Ce}$ (Fig. 10c) have a very rough oxidized film surface, and the cross section area was also found to decrease. Figure 11 shows the further enlargement of the fiber containing Ce. The oxidized film peeled off at many areas, and type $\mathrm{C}$ exhibited poorer film adhesion than the other two types of stainless steel. These results suggest that compared to the fibers containing $\mathrm{La}$ and $\mathrm{Y}$, the peeling off and regeneration of the $\mathrm{Al}_{2} \mathrm{O}_{3}$ film and formation of voids progress more quickly with the fibers containing $\mathrm{Ce}$ owing to its poor film adhesion.

Furthermore, X-ray diffraction of the fiber surface was performed to investigate the oxides generated in the oxidized surface film of stainless steel fibers processed at high temperature. Figure 12 shows the results. For the SUS304 stainless steel fibers, the oxidized surface film consists mainly of $\mathrm{Fe}$ and $\mathrm{Cr}$ oxides, which causes the oxidized film to peel off easily and oxidization to
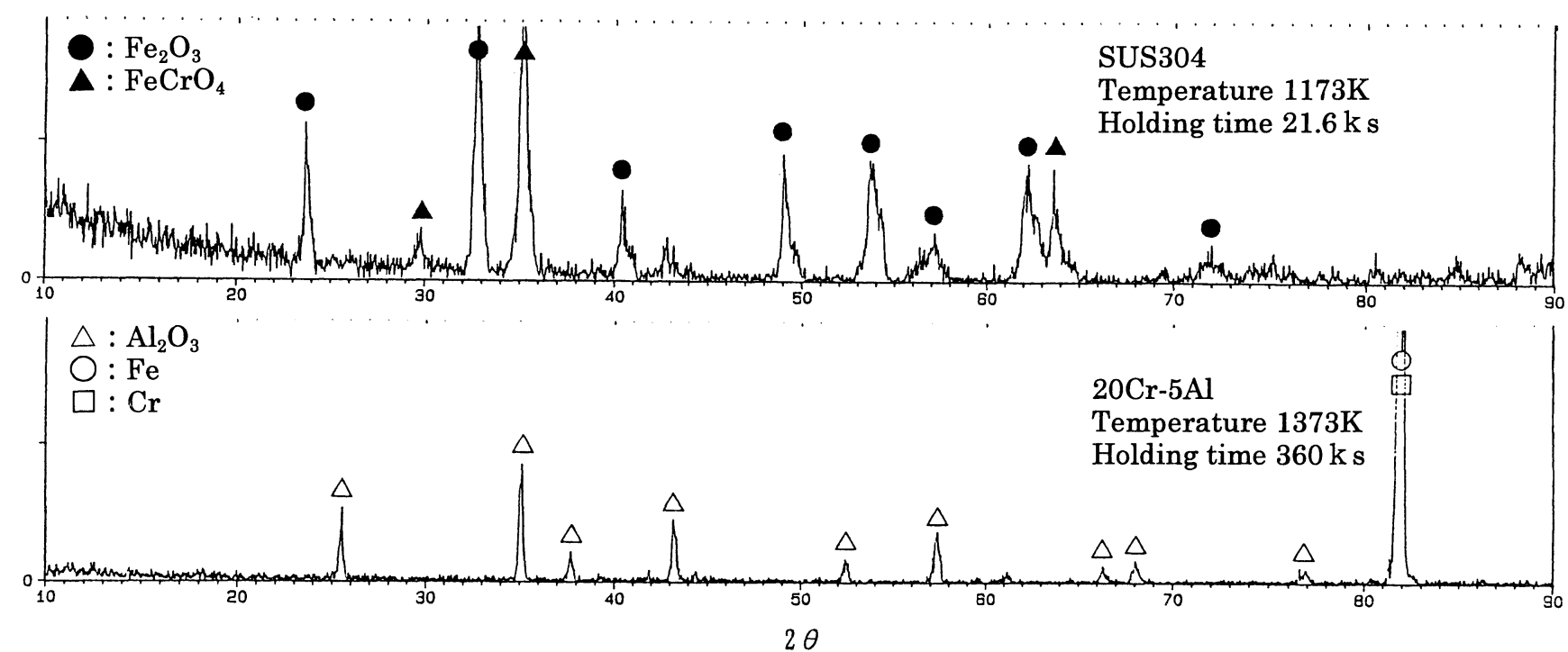

Top: SUS304, Temperature 1173K, Holding time 21.6ks, Bottom: 20Cr-5Al,Temperature 1373K, Holding time 360ks Fig. 12 X-ray diffraction pattern of fiber after heat durability test

could not be obtained. When the equivalent diameter was large, $85 \mu \mathrm{m}$, the fiber strength decreased with holding time similarly to the equivalent diameter of $35 \mu \mathrm{m}$, but at the holding time of $360 \mathrm{ks}$, type A showed a fiber strength of $200 \mathrm{MPa}$ while type $\mathrm{C}$ showed a fiber strength of $60 \mathrm{MPa}$, confirming that these two types of stainless steels have heat resistance which continues for a long period of time.

This is apparently because the fiber diameter of these stainless steels is large, and the advance of oxidized film inside is slowed down. Figure 10 shows the enlargement of the external view of the fiber under the conditions; equivalent diameter of $35 \mu \mathrm{m}$, processing temperature of $1373 \mathrm{~K}$, and holding time of $360 \mathrm{ks}$. The fibers containing La (Fig. 10a) and Y (Fig. 10b) were coated by oxidized progress inside, resulting in the powdery state. For the $20 \mathrm{Cr}-5 \mathrm{Al}$ stainless steel fiber containing a minute amount of rare earth elements, it was confirmed that the $\mathrm{Al}_{2} \mathrm{O}_{3}$ film was mainly generated on the fiber surface at the processing temperature and holding time of $1373 \mathrm{~K}$ and $360 \mathrm{ks}$, respectively, and this film helped control the generation of the $\mathrm{Fe}$ and $\mathrm{Cr}$ oxides. Although, small amounts of rare earth elements is known to affect the tightness and adhesion of the generated $\mathrm{Al}_{2} \mathrm{O}_{3}$ film ${ }^{[9]}$, the surface of the $\mathrm{Al}_{2} \mathrm{O}_{3}$ film did not show any significant dependence on the equivalent diameter as shown in Fig. 13. For the $20 \mathrm{Cr}-5 \mathrm{Al}$ stainless steel containing small amounts of $\mathrm{La}$ and $\mathrm{Y}$ the surface showed fine needle-like structures. On the other hand, the $20 \mathrm{Cr}-5 \mathrm{Al}$ stainless steel containing small amounts of $\mathrm{Ce}$ showed only a few 
needle-like structures, but numerous particle type structures causing poor tightness of the fiber. The voids observed, lack of tightness and adhesion, and progress of oxidization into the inside through the voids explain an abrupt decrease in the heat resistance of the type $C$ $20 \mathrm{Cr}-5 \mathrm{Al}$ stainless steel.
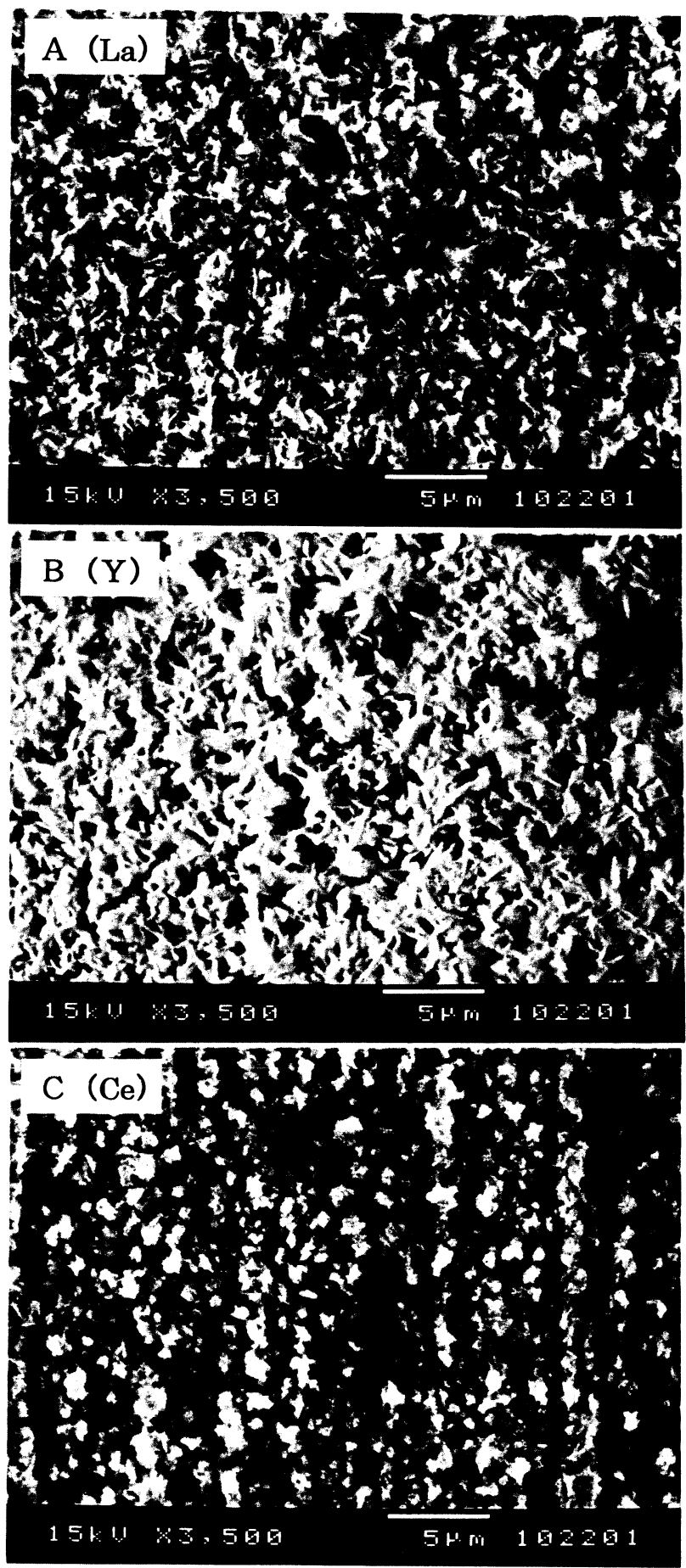

Temperature $1373 \mathrm{~K}$, Holding time $360 \mathrm{ks}$

Fig. 13 Morphology of oxidized layer surface

\section{Conclusions}

The following summarizes the results of the heat resistance against high temperatures for various stainless steel fibers produced by the hot water soluble resin coated coil shaving method.

(1)The normal SUS304, SUS316L, and SUS430 stainless steel fibers became brittle and powdery owing to the oxidization at the processing temperature of $1173 \mathrm{~K}$ and holding time of $21.6 \mathrm{ks}$.

(2)For fibers with equivalent diameter of $35 \mu \mathrm{m}$, the 20Cr-5Al stainless steels containing La and Y showed fiber tensile strength of about $150 \mathrm{MPa}$ even at a processing temperature of $1373 \mathrm{~K}$ and holding time of 360 ks, demonstrating the flexibility of fibers. However, the $20 \mathrm{Cr}-5 \mathrm{Al}$ stainless steel containing small amounts of $\mathrm{Ce}$ showed progress oxidization due to the peeling of the oxidized film, which caused the fiber to become brittle, and lose its shape.

(3)When the equivalent diameter was large $(85 \mu \mathrm{m})$, flexibility of the fiber was seen even at the processing temperature of $1373 \mathrm{~K}$ and holding time of $360 \mathrm{ks}$. It was also confirmed that outstanding heat resistance at high temperatures can be obtained.

(4)For the $20 \mathrm{Cr}-5 \mathrm{Al}$ stainless steel, it was confirmed that $\mathrm{Al}_{2} \mathrm{O}_{3}$ film mainly forms on the fiber surface owing to the controlled generation of $\mathrm{Fe}$ and $\mathrm{Cr}$ oxides.

(5)Tightness of the $\mathrm{Al}_{2} \mathrm{O}_{3}$ film arises from the types of rare earth elements contained. Compared to stainless steel fibers containing $\mathrm{Ce}$, those containing $\mathrm{La}$ and $\mathrm{Y}$ show outstanding tightness and as a result higher heat resistance.

\section{References}

[1]Hirai O.; Metal and Technology, 50,P.19 (1980)

[2]Nakagawa T., Yanagisawa A., and Suzuki K.; Journal of the Society Fiber and Technology Japan, 39, P.121 (1983)

[3]Kaneko M., Yanagisawa A., and Nakagawa T.; The Japan Society for Precision Engineering, 62, P.110 (1996)

[4]Kaneko M., Yanagisawa A., and Suzuki T.; Journal of the Textile Machinery Society of Japan, 49, T260 (1996)

[5]Ohoshi T., et.al.; Proceedings of 1993 Powder Metallurgy World Congress, P.1133 (1993)

[6]Kawano M., Ishii K., and Sato S.; The Japan Institute of Metals, Fall Meeting, P.1045 (1994)

[7]Hiramatsu N., and Uematsu Y.; Tetsu-to-Hagane, 81, P.1001 (1995)

[8]Nakamura S., Hiramatsu N., Shimizu I., and Uematsu Y.; Nisshin Steel Technical Report, 62, P.128 (1990)

[9]Hiramatsu N., and Stott F.H.; CAMP-ISIJ, 11, P.467 (1998) 